Psychological Medicine, 1980, 10, 1-3

Printed in Great Britain

\title{
EDITORIAL
}

\section{Choline, acetylcholine and dementia ${ }^{1}$}

Among the synaptic transmitters acetylcholine has never attracted much attention from those interested in the biological basis of mental and neurological disorder. While noradrenaline and serotonin have excited the interest of those treating depressed and psychotic patients for many years, and claims abound for the involvement of dopamine and the peptide transmitters in almost every psychopathology, acetylcholine, until recently, remained comparatively neglected. However, in the last few years, attempts at the modification of cholinergic function for the benefit of tardive dyskinetics, choreics and dements have become a minor industry.

The observations which have led to this boomlet have been both clinical and arising from attempts at therapy. The studies of Bird \& Iversen (1974), Aquilonius et al. (1975) and McGeer \& McGeer (1976) have shown that the activity of the enzyme choline acetyltransferase was low in various basal ganglia of the brains of choreic patients post mortem. Later, Bowen et al. (1976), Davies \& Maloney (1976), Perry et al. (1977) and White et al. (1977) showed that choline acetyltransferase activity was also reduced in the cerebral cortex of patients suffering from dementia (Alzheimer's disease). Choline acetyltransferase is the enzyme which converts choline to acetylcholine; so prima facie (but see below), it seems reasonable to suppose that a deficiency of the enzyme would result in a deficiency of the synaptic transmitter acetylcholine, and that the symptomatology might therefore arise because the cholinergic synapses in the brain cannot function properly.

The possibility of a cholinergic involvement in dementia has also been strengthened by reports that the administration of cholinesterase inhibitors (physostigmine) improves the learning and retention abilities both in experimental animals and in humans (Drachman \& Leavitt, 1974; Davis et al. 1978; Sitaram et al. 1978). Cholinesterase inhibition will prevent the breakdown of acetylcholine and therefore enhance its effectiveness at the synapse. There is, then, a superficial similarity between Alzheimer's disease, in which acetylcholine is presumed to be deficient in the cortex, and Parkinson's disease, in which the transmitter dopamine is known to be deficient in the basal ganglia and can be corrected by administration of L-dopa. The similarity is not exact but has been sufficient to encourage attempts at therapy by administering choline, the argument being that since choline is a precursor of acetylcholine, dietary elevation of the precursor will lead to increased levels of the transmitter in brain. Some amelioration of the symptoms of tardive dyskinesia has been reported (Growdon et al. 1977; Tamminga et al. 1977), but whether the strategy will be effective for dementing patients remains to be seen.

However, it might be worth standing back to consider what studies in experimental animals have told us about central cholinergic systems, before assuming that this is going to be a successful re-run of the L-dopa story. The cholinergic and dopaminergic systems are rather different from each other; a major difference is the ratio of synthetic ability to tissue stores of transmitter. Expressing this as the time taken for the synthesizing enzyme to replace the total tissue store, we find that this is about 1 hour for dopamine in the human caudate nucleus. Analogous figures for the cholinergic system in humans are not available because rapid post mortem degradation prevents reliable estimates of acetylcholine being made. In rodents the synthesizing enzyme can replace the tissue store in about 10-20 seconds, and there is sufficient similarity to this figure in other species to suggest that it is approximately correct for humans. This means, in effect, that there is a considerable surplus to normal requirement of choline acetyltransferase, and there are two important corollaries for the arguments concerning its deficiency in dementia. First, it does not follow from a deficiency of choline acetyltransferase that a deficiency of acetylcholine exists. Secondly, increasing the concentration of choline will only affect the amount of acetylcholine by mass-action (i.e. in direct ratio),

1 Address for correspondence: Dr R. M. Marchbanks, Department of Biochemistry, Institute of Psychiatry, De Crespigny Park, Denmark Hill, London SE5 8AF.

I

PSM IO

0033-2917/80/2828-4740 $\$ 01.00$ 단 1980 Cambridge University Press 
and then only if it can gain access to the cholinergic nerve cells. The problem of choline access is rather complicated; there is some experimental evidence to suggest that transport of choline, at least at the cellular level, is fairly responsive to the needs for acetylcholine and that the regulatory step is at the neuronal membrane.

But we do not need to extrapolate from theoretical arguments in order to see whether administration of choline will increase brain acetylcholine. This can easily be ascertained from experiments in animals and it is reasonable to assume (there being broad similarity of cholinergic organization between species) that the pattern of results will apply to humans as well. Despite the claims of Cohen \& Wurtman (1976) and Hirsch et al. (1978), it is by no means clear that choline in doses of up to approximately $1 \mathrm{mMole} / \mathrm{kg}$ (roughly equivalent of a dose to humans of $10 \mathrm{~g}$ ) affects brain acetylcholine concentrations, even though it raises plasma choline levels (Choi et al. 1975; Flentge \& Van den Berg, 1979). Nor does a choline dietary deficiency reduce brain acetylcholine (Haubrich et al. 1976). Apart from Hirsch et al., the only positive claim seems to be that of Kuntscherova (1972), who observed a $20 \%$ increase in brain acetylcholine following $1.2 \mathrm{mMole} / \mathrm{kg}$ choline given by injection to rats. The reason for these discrepancies is unclear, but it is noteworthy that, in the report by Hirsch et al. (1978), the controls of one of the two groups of animals have higher concentrations of acetylcholine in the caudate nucleus than the choline treated animals of the other group.

Even though the indications from choline acetyltransferase deficiency are ambiguous and the effects of choline administration uncertain, the psychopharmacological evidence does suggest a cholinergic involvement. What strategies might be used to capitalize on this in the interest of therapy? There seem to be two possibilities: to preserve the action of acetylcholine which has been functionally released at the synapse by administering anticholinesterase drugs; and to make more acetylcholine available, as is the expectation of choline therapy. The major problem concerning the former is that the peripheral side-effects of physostigmine usually have to be prevented by simultaneous administration of methyl-scopolamine. It would be very helpful if pharmacological legerdemain could provide an anticholinesterase which only acted centrally.

As will have become apparent, it is not easy to persuade the brain to make more acetylcholine; however, it might be worth taking advantage of the fact that the average diet contains the equivalent of $1-3 \mathrm{~g}$ of choline in the form of lecithin from which it is released by hydrolytic enzymes in the liver. Dietary lecithin could be readily increased by a meat, fish and egg rich diet. One of the puzzles of choline metabolism is the fate of the dietary choline. The phospholipids which contain most of the choline in the body are structural components of the cell membrane. They exist in a steady state so that in the adult any dietary choline will be surplus to other than occasional requirement. There is an enzyme in the liver (choline oxidase) which initiates the breakdown sequence of choline to betaine, thence glycine and $C_{1}$ units. Little is known about this enzyme and whether the surplus choline is indeed metabolized by this route. It would repay investigation because, if the metabolism of choline could be blocked by the administration of a suitable inhibitor of choline oxidase, large amounts of dietary choline might then be available for diversion towards the synthesis of acetylcholine. Naturally, any beneficial effects of administered choline would also be enhanced by such treatment.

R. M. MARCHBANKS

\section{REFERENCES}

Aquilonius, S. M., Eckernäs, S. A. \& Sundwall, A. (1975). Regional distribution of choline acetyltransferase: changes in Huntington's chorea. Journal of Neurology, Neurosurgery and Psychiatry 38, 669-677.

Bird, E. O. \& Iversen, L. L. (1974). Huntington's chorea. Post mortem measurement of glutamic acid decarboxylase, choline acetyltransferase and dopamine in basal ganglia. Brain 97, 457-472.
Bowen, D. M., Smith, C. B., White, P. \& Davison, A. N. (1976). Neurotransmitter-related enzymes and indices of hypoxia in senile dementia and other abiotrophies. Brain 99, 459-496.

Choi, R. L., Freeman, J. J. \& Jenden, D. J. (1975). Kinetics of plasma choline in relation to turnover of brain choline and formation of actylcholine. Journal of Neurochemistry 24, 735-741.

Cohen, E. L. \& Wurtman, R. J. (1976). Brain acetylcholine: control by dietary choline. Science 191, 561-562. 
Davies, P. \& Maloney, A. J. F. (1976). Selective loss of central cholinergic neurons in Alzheimer's disease. Lancet ii, 1403.

Davis, K. L., Mohs, R. C., Tinklenberg, J. R. \& Pfefferbaum, A. (1978). Physostigmine: improvement of long-term memory processes in normal humans. Science 20, 272-274.

Drachman, D. A. \& Leavitt, J. (1974). Human memory and the cholinergic system. A relationship to ageing. Archives of Neurology 30, 113-121.

Flentge, F. \& Van den Berg, C. J. (1979). Choline administration and acetylcholine in brain. Journal of Neurochemistry 32, 1331-1333.

Growdon, J. H., Hirsch, S. B., Wurtman, R. J. \& Wiener, W. (1977). Oral choline administration to patients with tardive dyskinesia. New England Journal of Medicine 297, 524-527.

Haubrich, D. R., Wang, P. F. L., Chippendale, T. \& Proctor, E. (1976). Choline and acetylcholine in rats: effect of dietary choline. Journal of Neurochemistry 27, 1305-1313.

Hirsch, M. J., Growdon, J. H. \& Wurtman, R. J. (1978). Increase in hippocampal acetylcholine after choline administration. Brain Research 125, 383-385.
Kuntscherova, J. (1972). Effect of short-term starvation and choline on the acetylcholine content of organs of albino rats. Physiologia Bohemoslov 21, 655-660.

McGeer, P. L. \& McGeer, E. G. (1976). Enzymes associated with the metabolism of catecholamines, acetylcholine and GABA in human controls and patients with Parkinson's disease and Huntington's Chorea. Journal of Neurochemistry 26, 65-76.

Perry, E. K., Perry, R. H., Blessed, G. \& Tomlinson, B. E. (1977). Necropsy evidence of central cholinergic deficits in senile dementia. Lancet i, 189.

Sitaram, N., Weingartner, H. \& Gillin, J. C. (1978). Human serial learning: enhancement with arecholine and choline and impairment with scopolamine. Science 201, 274-276.

Tamminga, C. A., Smith, R. C., Ericksen, S. E., Chang, S. \& Davis, J. M. (1977). Cholinergic influences in tardive dyskinesia. American Journal of Psychiatry 134, 769-774.

White, P., Goodhart, M. J., Keet, J. P., Hiley, C. R., Carrasco, L. H., Williams, I. E. I. \& Bowen, D. M. (1977). Neocortical cholinergic neurons in elderly people. Lancet $\mathrm{i}$, $668-670$. 